\title{
ONOMAREDIN
}

Journal of linguistics, philology and translation

\section{On Placement and Removal Events in Ilami Kurdish: A Cognitive-Typological Approach}

\author{
Amir Karimipour \\ University of Isfahan \\ Iran

\section{Vali Rezai} \\ University of Isfahan \\ Iran
}

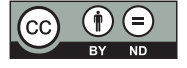

Amir Karimipour: Department of Linguistics, University of Isfahan, Isfahan, Iran.

| E-mail:am.karimipour@fgn.ui.ac.ir

Vali Rezai: Department of Linguistics, University of Isfahan, Isfahan, Iran. | E-mail:vali.rezai@fgn.ui.ac.ir 


\section{Abstract}

This paper explores the linguistic characteristics of placement and removal events in Ilami Kurdish and investigates the Goal-over-Source predominance hypothesis in such events. By testing the asymmetry hypothesis in placement vs. removal events, we determined that various predicates are used to encode these events in Ilami Kurdish. Data were collected using a set of video clips including the 'put and take' stimuli (Bowerman et al., 2004) with ten Ilami Kurdish speakers, who described the occasions when placement and removal events were required. The results of this first experiment show that there are asymmetric correlations between placement and removal events in terms of verbal predicates. In fact, proportionally more fine-grained types of placement predicates are observed in the descriptions of the Kurdish consultants. Accordingly, it can be concluded that placement events, in comparison with removal events, are cognitively more salient and intricate in the mind of Kurdish speakers, which is directly connected with such linguistic distinctions as properties of the figure, force-dynamic notions, and manner of motion, which are more determinant in placement events than removal events. In the next part of this study, the Goal-over-Source predominance hypothesis was explored in placement and removal events. This hypothesis was tested on the basis of linguistic descriptions as well as a memory task. In the descriptive task, a set of video clips of placement and removal events, including different source and goal paths, was used. Respondents participating in this experiment described each scene after they watched it. In the memory task, participants were asked to watch the scenes of placement and removal events as well as matched events and then judge whether source or goal components can be matched or not. It was found that in these tasks, the goal component was mentioned more often and more accurately matched, respectively. These findings support the Goal-over-Source predominance hypothesis and highlight the cognitive importance of the goal component in placement events compared to the source component in removal events.

Keywords: Ilami Kurdish; cognitive-typology; placement event; removal event; goal component; source component. 


\section{Introduction}

It has been claimed that the world's languages differ in many ways such as the ways in which they classify events, the granularity with which they divide up a particular semantic domain, the types of distinctions that make a semantic difference warranting a distinct lexical item, and the location in the clause where particular spatial information is encoded (Talmy, 1985, 2000; Majid \& Bowerman, 2007, as cited in Brown, 2012: 55).

In the lexicalization pattern typology suggested by Talmy (1985), many languages are catalogued as either a verb-framed language or a satellite-framed language. Verb-framed languages typically encode information about the path of motion in the main verb. In contrast, satellite-framed languages encode the path of motion through "satellites" to the verb, such as verb particles in English, Thus, the verb slot is filled by the manner component. Nevertheless, some languages cannot be classified as purely satellite-framed or verb-framed languages due to blurry situations.

This leads Slobin (2004) to reject Talmy's dual distinction and to propose revisions to this typology. Thus, he proposes a third class of equipollently-framed languages that include several types of languages: languages such as Thai and Mandarin Chinese with serial verb constructions in which a Manner verb is often expressed together with a Path verb, languages with bipartite verb constructions like Algonquian and Hokan, and languages with Manner preverb + Path preverb + verb like Jaminjungan languages (Hickmann et al., 2012).

Talmy (2000) analyzes that the basic "Motion event" comprises of four components: a "Figure" moving or located with respect to another object which is called the "Ground". Besides Figure and Ground, there are Path and Motion. The Path is the path followed or site occupied by the Figure object with respect to the Ground object. The component of Motion refers to the presence of motion or locatedness in the event. In addition to these internal components, a Motion event can be associated with an external "Co-event" that usually bears the relation of Manner or of "Cause" to it (Talmy, 2000: 25). The following example could illustrate the point:

(1) Harry walked quietly down the stairs.

In the above example, Harry is the Figure, the Ground is the stairs and down is the Path. The verb to walk expresses simultaneously the fact of Motion, which is called the "framing event" and the Manner of motion or Co-event (Cifuentes Férez, 2008).

The present paper focuses on a special kind of events, namely 'placement' and 'removal' events. Therefore, it seems necessary to give the characteristic features of these events. Talmy argues that a placement event has the four basic semantic components of a motion event, namely, Figure, Ground, Path, and Motion (Talmy, 1985, 2000). Placement events occur when 
an object is placed with some degree of manual control onto some Ground. As compared with placement events, removal events are those where an object is removed with some degree of manual control from some Ground. (Gullberg \& Burenhult, 2012).

Gleitman (1990: 30) clarifies that a placement event has a semantic and syntactic structure. In support of her claim for universal alignments of syntax and semantics, she argues for the universal naturalness of three arguments for 'put' verbs (a putter, a puttee, and a location). Goldberg et al. (2004) claim that across the world's languages, 'put' is the canonical verb that best represents the meaning of the caused motion construction (“X CAUSES Y TO MOVEZ"). The following diagram shows the construction of placement events (as cited in Brown, 2012: 55-56).

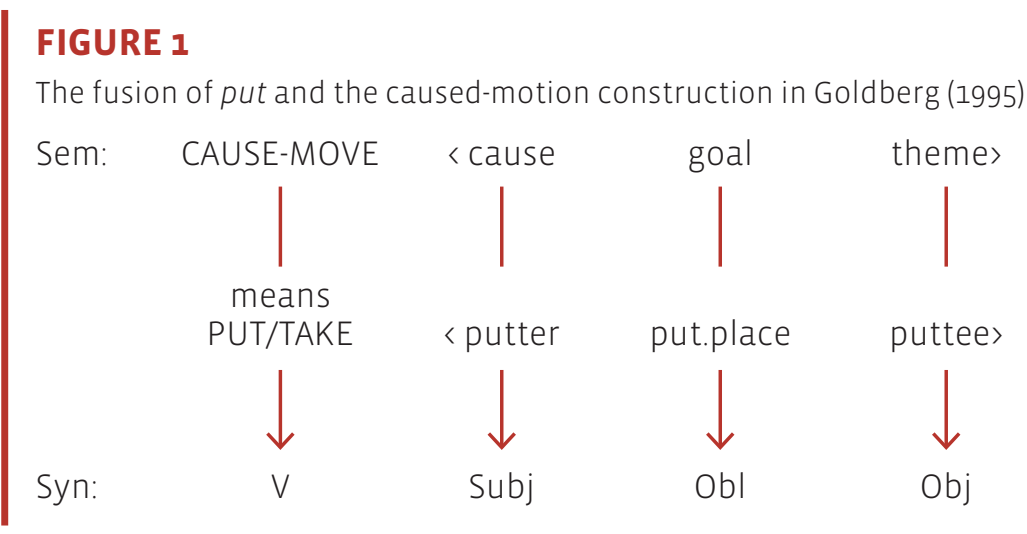

The semantics related directly with the construction is CAUSE-MOVE 〈cause goal theme), while PUT <putter, put, place, puttee is associated with the verb. The semantic roles associated with the construction (=argument roles) are fused with those associated with the verb (=participant roles). This leads to the three participant roles of put being placed in correspondence with the argument roles, leading to the composite fused structure (Iwata, 2008: 5).

The study of placement and removal events has attracted the attention of scholars in the recent decades. Burenhult (2012) studies the encoding of placement and removal events in Jahai. It is claimed that the descriptions of placement and removal events are structurally similar in this language. On the whole, it is concluded that, on the basis of semantic parameters, Jahai speakers subcategorize placement/removal events into relatively distinct situation types, such as putting/taking, inserting/extracting, dressing/undressing, and placing/retracting one's body parts. It is also observed that the borders of these situation types are not clearly defined, as the distinction between putting and taking and inserting and extracting events is fluid.

Ibarretxe-AntuÑano (2012) examines the lexicalization and conceptualization of the aforementioned events in the context of Basque and Peninsular Spanish. The research reveals that speakers talk about these events in the same manner, which involves using a verb encoded with lexical information about the activity performed and a group of cases/spatial nouns or 
prepositions/adverbs indicating the position or change of location of the ground. Additionally, it is also demonstrated that there is dissymmetry between placement and removal events, as the former are more diverse in both Basque and Peninsular Spanish. Finally, the paper focuses on several conceptual elements, such as agentivity, intentionality and force-dynamic notions that appear to play pivotal roles in the conceptualization of the aforesaid events.

O'Connor (2012) also investigates the structural and semantic features of placement and removal events in the Lowland Chontal of Oaxaca, stating that, in this language, the majority of caused motion event descriptions involve compound stem predicates that hold information about the types of figure and ground as well as their spatial relations at the endpoint of motion. Furthermore, she claims that argument ellipsis frequently occurs in this language, and this can be observed in different event descriptions. Concerning the different patterns of figure and ground realization with respect to event type and predicate type, it is also stated that, generally, lexical figures are more frequent than lexical grounds in this language. Unlike Spanish and Basque, it seems that force and intention do not play a pivotal role in the patterns of argument realization; however, they can be considered as the factors, which contribute to the asymmetry hypothesis in placement vs. removal events.

Petersen (2012) investigates the linguistic encoding of 'put' and 'take' events in Kalasha, an Indo-Aryan language spoken in Northwest Pakistan. He argues that the asymmetry hypothesis in placement vs. removal events is attested at different levels in this language; however, this asymmetry can be observed in favor of put expressions or in favor of take expressions. Petersen (2012) makes clear that 'take' predicates are more numerous and diverse in the language compared to 'put' predicates, however, when it comes to the use of the postposition kai in locative constructions, put events show more degree of diversity.

Lakusta and Landau (2012) assess the descriptions of motion events to see if the Goalover-Source predominance hypothesis observed in language has a cognitive basis. 4-year-old children and adults are recruited for descriptive and memory tasks. The results reveal that the linguistic asymmetry between goal and source is partially rooted in non-linguistic event representations. As for the linguistic asymmetry between goal and source, it is shown that the goal-bias principle is defensible; however, the non-linguistic memory for events shows the goal-bias only for those events involving animate, goal-directed motion.

As stated earlier, this paper attempts to explore the linguistic features of placement and removal events in Ilami Kurdish and further investigate the Goal-over-Source predominance hypothesis in this dialect of Kurdish, adopting a cognitive-typological approach. The main questions which will be investigated in the study are as follows:

1) Is there a widespread asymmetry in the linguistic encoding of placement and removal events (Narasimhan et al., 2012) in Ilami Kurdish and which factors are motivating in this respect? 
2) Is the Goal-over-Source predominance hypothesis attested in the Ilami Kurdish placement and removal events as far as a descriptive task is taken into account? Is this potential goal-bias supported in a memory task, too?

This paper has the following outlines: In section (1), theoretical bases of the study were presented. A brief overview of the Kurdish language and its varieties is given in section (2). In section (3), Ilami Kurdish data are analyzed. Finally, in section (4), concluding remarks of the study will be pointed out.

\section{Kurdish language}

Speakers of Kurdish, a new western Iranian language, are dispersed across broad geographical areas of Iran from the west, encompassing Kurdistan, western Azerbaijan, Kermanshah and Ilam, to the east (Khurasan), Iraq, eastern and southeastern Turkey and Syria. Kurdish speakers have also settled to the east of the Caspian Sea, in Central Anatolia as well as in Armenia, Azerbaijan and Turkmenistan. Based on approximations, Turkey, Iran and Iraq shelter 43, 31 and 18 percent of Kurds, respectively, while 6 percent of Kurds live in Syria and the remaining 2 percent live in the former Soviet Union, mainly in Armenia and Azerbaijan (Gunter, 2004: XXV-XXvi).

The Kurdish language has three main dialects. First, northern Kurdish dialects, usually called Kurmanji, are spoken in northwest Iraq, Turkey, Khurasan, in Iran (Gunter, 2004: xxV-xxvi). Second, central Kurdish has two main dialects, namely Mukri, which is spoken in Iran, to the south of Lake Urmia, and Sorani, mainly used to the west of the Mukri region in the province of Erbil, Iraq. Finally, southern Kurdish comprises different dialects such as Ilami, Kermanshahi, Laki, Garusi and Sanjabi (Mackenzie, 1963; Oranskij, 1979: 35-36; Asatrian, 2009: 12).

Ilami, an under-resourced dialect, is one of the Kurdish varieties, which is spoken in Ilam, a small mountainous city in western Iran. This dialect has a rather rich inflectional system. For example, main passive construction, present perfect and pluperfect are all inflectionally formed in this dialect. By the way, llami like many Iranian varieties has lost its gender and case marking systems in nouns and pronouns. This can be considered as a sharp distinction in comparison with the owning varieties of Kurmanji, which mark gender and/or different cases. In contrast, Ilami has pronominal affixes used to construct case relations which are not usually found in northern dialects of Kurdish (see Bynon, 1979).

\subsection{Structural preliminaries of placement and removal events in Ilami Kurdish}

In this part, the syntactic features of Ilami three-place verbs including placement and removal events are discussed. The default syntactic pattern of three-place verbs is represented below: 
(SUBJ) DIRECT OBJECT VERB: SUBJAGR OBLIQUE ARGUMENT

In this construction, the first element, the subject, precedes the direct object as the Theme. The verb of the sentence is the predicating element preceding the oblique object. The following llami example could be illustrative:

(2) kwar-ce tup-ce da rafiq-e.

boy-def ball-def give.PST.3SG friend-POSS.

'The boy gave the ball to his friend.'

It should be emphasized that [NP NP VP PP] frame is the "basic" pattern for such events. In certain contexts, due to pragmatic factors, the word order might change and/or some elements may elliptically drop. As the result of this omission, the obligatory elements attach to the verb in the form of object particles, oblique particles, etc. For example, focusing on the direct object, Kurdish speakers can topicalize the direct object "tup-ce" (ball) appearing at the front of the sentence:

\section{(3) tup-ce kwar-ce da raefiq-e.}

ball-def boy-DEF give.PST-3Sg friend-POSS.

'The ball, the boy gave to his friend.'

Unlike some languages including Jahai (Burenhult, 2012), which have identical syntactic pattern for both events, Ilami Kurdish encodes these events differently. In Ilami Kurdish, placement and removal events are always goal- and source-marking, respectively. As illustrated in (4), for placement event the [NP NP VP PP] frame mentioned above can be taken into account. However, for removal event, a minor modification is required.

DROP APPLE INTO BAG [\#012]

(4) sēf-ce na nam-ə kisce- -2 .

apple-def put.PST-3sg in-EZ2 bag-DEF.

'[The man] put the apple into the bag.'

Example (4) consists of an optional subject preceding a direct object. In some contexts, the direct object may be omitted and instead be expressed through a bound pronoun attached

1 The numbers accompanying the examples refer to the video-clips in the stimuli set developed at the Max Planck Institute for Psycholinguistics in Nijmegen (Bowerman et al., 2004).

2 Ezafe (=EZ) is a grammatical particle which can be used in different contexts. For example, it can link the possessor and the possessed in possessive constructions. 
to the verb. Importantly, the oblique object, which encodes goal information and follows the main verb may be expressed either through a free lexical item or a bound pronoun attached to the satellite accompanying the main verb.

(5) sēf-ce doe nam-ə (kisce-ce) dar-award. apple-def from in-EZ bag-DEF out-bring.PST.3SG.

'[The man] took the apple out of the bag.'

(6) kataw-ce (dce ban-a maz-ce) hezda.

book-DEF from above-EZ table-def lift give.PST.3SG.

'[He] grabbed the book off the table.'

(7) kif-ce (dce does-ə zən-œ)

purse-def (from hand-EZ woman-DEF) snatch.PST.3SG.

'[The thief] snatched the woman's purse.'

On the other hand, examples (5) through (7), as removal events, share [NP NP PP VP] as their syntactic frame. In Ilami Kurdish, the ellipsis of source information is prevalent. In other words, unlike goal information in placement events, there is a dispute whether this information should be considered as an oblique object or an adjunct. By considering the information provided above, it can be said that in both placement and removal constructions, the verb and its subject-object particles together form the obligatory constituents of such clauses, that is, the core of the clause.

\section{Data analysis}

This section encompasses two experiments. In experiment (1), characteristic features of placement and removal events will be pointed out. Particularly, we aim to determine if the asymmetry hypothesis in placement vs. removal events is supported in Ilami Kurdish. In experiment (2), we attempt to probe 'the goal-over-source hypothesis' at both linguistic and memory levels to show if this hypothesis is attested in the mentioned levels. It is noteworthy that for the presentation of Ilami data, three levels including IPA-transcription (line 1), literal translation (line 2) and idiomatic translation (line 3) are presented.

\subsection{Experiment (1): Probing the asymmetry hypothesis in Ilami placement vs. removal events}

As shown, most previous studies in the domain of placement and removal events (e.g. Narasimhan et al., 2012) have supported the asymmetry hypothesis in placement vs. removal 
events in different languages. In this part, we investigate this asymmetry hypothesis in Ilami Kurdish placement vs. removal events. Furthermore, the semantic features of these event types with an eye to some motivating factors will be elucidated.

\subsubsection{Stimuli and participants}

In this experiment, ten consultants from different dialectal areas of Ilam, who were proficient in Ilami Kurdish, responded to a set of stimuli (Bowerman et al., 2004) consisting of 63 short video clips portraying placement and removal events (e.g., 'put cup on table' vs. 'take cup off table'). It is worth mentioning that three of the videos were warm-up clips used to acquaint the participants with the research procedure. Participants were all over 30 years old of both genders (five males and five females). When selecting the participants, we preferred to recruit only those participants, who were native speakers of Ilami and used it in their daily conversations.

\section{FIGURE 2}

Ilami Kurdish participants responded to a set of video stimuli portraying placement and removal events

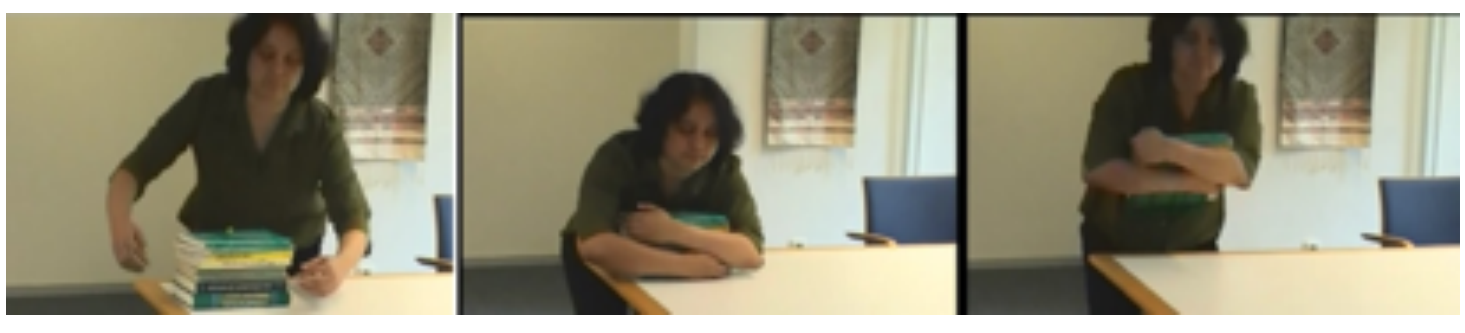

\subsubsection{Procedure}

As there are three versions of the video-set available, in order to maintain consistency throughout the paper, the scene numbers are based on the first version of the stimuli set. Data were recorded through a microphone connected to a laptop. Participants were requested to describe the scenes displayed on the laptop screen. It was also attempted to manage their descriptions, through asking the Kurdish equivalent of "what the person did?", in case they did not focus on the caused motion event. Afterwards the data were transcribed, using International Phonetic Alphabet (IPA) and analyzed according to certain examinations, including the asymmetry hypothesis in placement vs. removal events and semantic specificity of either of the events. It might be worth mentioning that in the analysis of the Kurdish data, authors might intuitively give additional and alternative instances to illustrate the point more obviously. The reason why the mentioned elicitation tool was chosen for this experiment is based on the premise that first this set of stimuli is standardized and peculiarly designed for investigating placement and removal events, and second our Kurdish data can be typologically compared with other languages, too. 


\subsubsection{Results and discussion}

There are two general verbs used to describe placement and removal events in Ilami. Used for a remarkable number of placement and removal events, najon and hez dajan, which are respectively equal to English "putting" and "picking" can be considered as the general verbs for such events. Importantly, for both placement and removal events, more specific verbs are also frequently used in Ilami, each of which conveys a more fine-grained concept respecting, for example, speed of placement/removal, solidity/liquidity of the Figure, etc. (see section 3.1.4).

The following table represents the verbs used for describing different placement and removal events. The verbs are ordered based on their frequency in the descriptions. Another characteristic worth mentioning is that specification of basicness of an expression is actually a reflection of frequency (Bybee, 2001). Based on this view, the first verb in each of the classes below can be considered as the basic verb of the event.

\section{TABLE 1}

Kurdish placement and removal verbs used

\section{TYPE OF VERB KURDISH VERBS USED}

\section{Placement verbs (27 types)}

\begin{tabular}{|c|c|}
\hline & 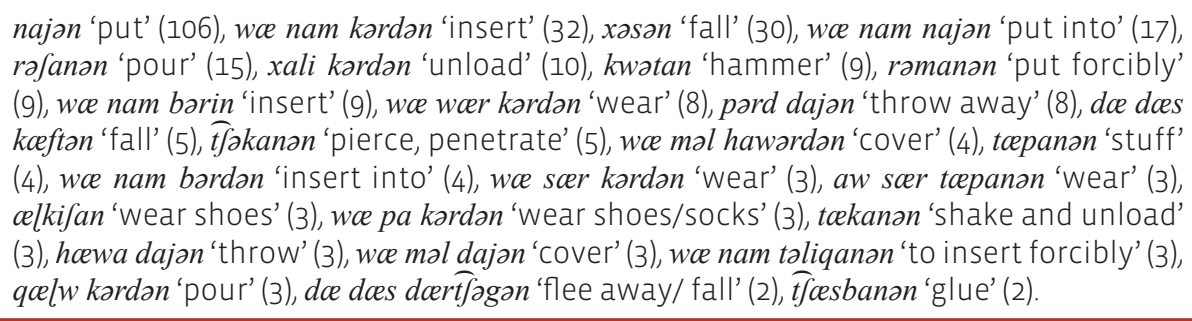 \\
\hline \multirow{2}{*}{ Removal verbs } & (11 types) \\
\hline & 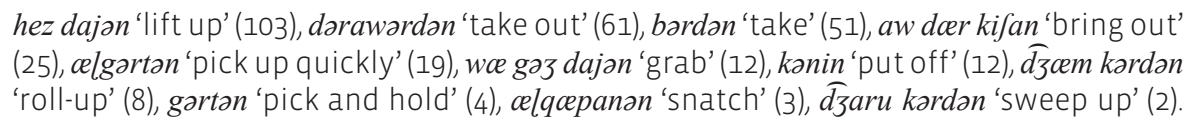 \\
\hline
\end{tabular}

According to table 1, najon 'put' and hez dajon 'lift up' are 106 and 103 times repeated in the corpus, respectively. On the basis of this frequency, the two predicates mentioned above are the general putting and taking verbs in Ilami. Moreover, our data show that there is an asymmetry between placement and removal events. There are 27 and 11 detected types for placement and removal, respectively. It appears safe to say that placement class includes more verbs conceptualizing various manners of motion. It should be mentioned that there are constructional and semantic overlaps amongst placement, inserting and dressing events, on the one hand, and removal, extracting and undressing events, on the other, all of which are divided in two respective broad placement and removal classes. For example, due to the productivity of 
the general placement verb najon, this verb functions as a "base" in the construction of some of the inserting compound verbs, too.

Typologically, Ilami Kurdish is similar to many other languages, which support the asymmetry hypothesis in placement vs. removal events. For example, Spanish, Basque, łAkhoe Haillom, Polish, Hungarian, Tzeltal, Kuuk Thaayorre, Chontal and Swedish all support the asymmetry between the linguistic encoding of placement and removal events. All the mentioned languages encode a greater number of placement verbs (Narasimhan et al., 2012). For example, there are 19 and 29 types detected for placement verbs in Basque and Spanish, respectively, while only 7 and 11 types are identified for removal verbs in the respective languages (Ibarretxe-AntuÑano, 2012). This is also the case in Swedish. In this language, placement descriptions are characterized by the use of semantically specific verbs (lagga "lay", satta "set", and stoppa "put into"), whereas removal descriptions are dominated by a single, more general verb (ta "take") (Gullberg \& Burenhult, 2012). Such distinctions as suspension, adhesion, animacy, properties of the figure and the ground, manner, and force-dynamic notions such as control, force, intentionality greatly influence the linguistic categorization of placement events across the world's languages, however, there are still language-specific patterns found in a few other languages such as Jahai and Kalasha, suggesting that such asymmetric pattern may not be universal (Narasimhan et al., 2012). Concerning the asymmetry observed in the variation of the Kurdish placement and removal verb classes, it seems logical enough to say that placement is a cognitively more salient event for Kurdish speakers, which is claimed to be a universal tendency (Narasimhan et al., 2012). The remarkable variation observed in the placement verb class is affected by several semantic distinctions including 'manner of motion', 'nature of the agent' and 'force-dynamic notions', which are more subtle in such events. Some of these semantic distinctions are presented in the following subsections.

\subsubsection{The nature of the figure}

According to our Kurdish corpus, it becomes clear that some traits concerning the figure can be determinant in using one type of placement/removal verb.

\subsubsection{Rigid vs. flexible}

By analyzing our Kurdish corpus, we find out that rigidity or flexibility of the figure object is determinant in choosing a more fine-grained verb. Consider the following examples:

PUT CANDLE INTO CANDLE STAND [\#014]

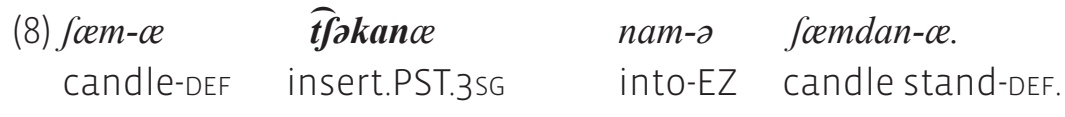

'[She] inserted the candle into candle stand.' 
In example (8), since the figure object is a long thin vertical and probably sharp object, $\bar{t}$ akanan "insert" will be the winning candidate of the competition. Importantly, this verb can be used, when the ground is a flat surface or containing object. In the former case, the final result of the event might be a scratch on the surface.

When we deal with a wide horizontal round object, the aforementioned verb is by no means appropriate. Instead kwatan "toss" seems to be a proper choice:

TOSS BOOK ON FLOOR [\#010]

(9) kataw-ce kwata zomin.

book-deF tosS.PST.3SG land.

'[He] tossed the book on the floor.'

In this context, the manner of the motion is also inferable. In fact, by doing this action, one can infer that the agent of the action has been angry or in a special mood caused the figure object to move speedily. The high rate of the event can be realized in removal events too. The examples given below illustrate this point:

(10) kataw-ce doe ban-a maz-ce celqcepan.

book-DEF from above-EZ table-def grab.PST.3SG.

'[He] grabbed the book off the table.'

(11) da gaz- $\quad$ o kataw-ce.

give.PST.3sG on- EZ book-DEF.

'[He] grabbed the book.'

Examples (10) and (11) both represent contexts, in which the agent of the action grabs the book quickly. However, there is a neat distinction in the meaning of these predicates, which might be of importance. The former portrays a situation, in which the agent picks up the object quickly, while the latter not only provides the manner of motion (i.e. high speed), but also predicts the next movement of the agent, too (i.e. running away).

As for inserting events, different verbs, based on the context, can be used. The following examples will help to illustrate this point:

STUFF RAG INTO CAR EXHAUST PIPE [\#017]

(12) partf-ce na nam-a egzaz-ce.

cloth-def put.PST.3sg into-EZ exhaust-Def.

'[He] stuffed the rag into the car exhaust.'

In example (12), the general verb najon "put" is used to depict the motion of a small flexible figure object, which inserts into a container effortlessly. 
(13) mil-ce kardce/barijoe nam-e.

rod-DEF insert.PST.3SG into-EZ it.

'[He] fully inserted the rod into it.'

PUT HAND INTO HOLE IN TREE [\#023]

(14) does-a kardce/barijoe nam-a dar- $a$.

hand-EZ put/insert.PST.3SG into-EZ tree-DEF.

'[She] put her hand into the tree hole.'

Examples (13) and (14), on the other hand, describe contexts in which (taller) less flexible figure objects are inserted into the Grounds. If the motion leads to a rapid full insertion of the object, barin "insert", otherwise kardan "put" along with the obligatory satellite nam "into", will be used.

Moreover, when najon "put" is used, it implies that the figure object will remain there for a given period of time, but this concept is not necessarily true regarding barin "insert" or kardan "put":

PUT HEAD INTO BUCKET [\#024]

(15) scer kardoe nam-a dul-ce.

head insert.PST.3ss into-EZ bucket-EZ.

' $[\mathrm{He}]$ inserted his head into the bucket.'

(16) scer na nam-a dul-ce.

head put.PST.3sg into-EZ bucket-DEF.

'[He] put his head into the bucket and kept it for a while.'

In example (15), there is no encoded concept regarding the temporal aspect of the motion, but in example (16), the concept of "keeping head in the bucket", along with the inserting event, is also inferable.

\subsubsection{Granular vs. liquid vs. solid}

The nature of the figure object (i.e. granular, liquid or solid) is also determinant in choosing one kind of placement or removal verb in llami. The following examples are illustrative:

POUR WATER OUT OF TIN [\#120]

(17) aw-ce rafance mol-a zoemin-ce.

water-def pour.PST.3sg on-EZ land-def.

'[S/he] poured the water on the floor.' 
As seen in example (17), the verb rafanan "pour" can be used to describe the motion of a liquid object. Furthermore, wa nam kardon "put" and najon "put" are also used, when the figures are granular (18) and solid (19) objects, respectively.

PUT FISTFUL OF RICE ON TABLE [\#005]

(18) meft-e barendु3 kardae ban-a maz-ce.

fistful-EZ rice put.PST.3sg on-EZ table-def.

'[S/he] put a fistful of rice on the table.'

PUT APPLE IN BOWL [\#011]

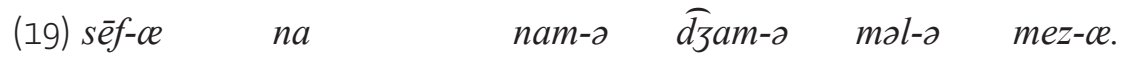

apple-def put.PST.3sg into-EZ bowl-def on-EZ table-def.

'[She] put the apple on the bowl which was on the table.'

In example (19), the use of the satellite nam "into" seems to be obligatory. Otherwise, the verb, as pointed earlier, would be a general item with an irrelevant meaning.

Regarding removal verbs, there are also a few predicates which are used, based on the nature of the removed figure:

(20) barenḑ3-ce jeemaw kard.

rice-def collect do.PST.3SG.

'[The person] rolled up the rice.'

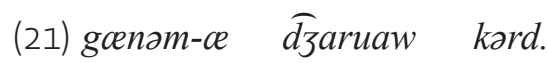

wheat-def sweep do.PST.3SG.

'[The person] swept up the wheat.'

The removal verbs presented in examples (20) and (21) are both used to describe the motion

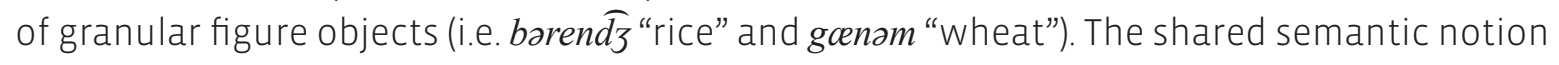
of (20) and (21) sunders, as the former does not provide any further information whether the figure object is cleanly removed from the source ground, while the latter does. Example (21) definitely implies that all the wheat seeds are removed from the surface.

\subsubsection{3. (Un)intentionality of the agent}

Regarding Ilami placement verbs, it seems that three criteria including "intentionality", "agency" and "force dynamics" proposed by Ibarretxe-AntuÑano (2012) also play pivotal roles in this dialect. As far as agency is taken into account, it seems that it has something to do with intentionality and force dynamics. Put it differently, there are some contexts in which the doer or agent of the motion is a separate entity, while in other cases the agent and the figure object are 
the same. Naturally, in those cases where agent and Figure are a single entity, the intentionality of the agent is at its minimum level; conversely, when the agent is a separate entity, the probability of intentionality of the motion is much higher. Look at the following illustrations:

DROP BOOK ACCIDENTLY ON FLOOR [\#009]

$\begin{array}{lll}\text { botaw-ce } & \text { xas- } & \text { zomin. } \\ \text { book-DEF } & \text { throw.PST.3sG-towards } & \text { land. } \\ \text { '[He] threw away the book.' } & \end{array}$

(23) kataw-ce doe does-e koeft.

book-DEF from hand-EZ fall.PST.3SG.

'[He] dropped the book on the floor.'

Examples (22) and (23) depict a single motion from different perspectives. In the former, the agent of the action throws the book intentionally, while in the latter case, the agent and the figure object are the same and thus the intentionality of the agent is cancelled. The following verb conceptualizes the high speed of the motion, in addition to the unintentinality of the agent:

(24) kataw-ce doe does-e doer tfag.

book-DEF from hand-EZ out flee.PST.3sG.

'The book fell down.'

Nonetheless, if the figure object is in liquid form, none of the above verbs can be used. There are three other main options, which can be used based on the intentionality criteria:

\section{SPILL WATER ONTO TABLE WHEN PICK UP GLASS [\#021]}

(25) aw-ce xali kard.

water-def emptydo.PST.3SG.

'[He] poured the water.'

(26) aw-ce rafan.

water-def pour.PST.3SG.

'[He] poured the water.'

(27) aw-ce qalw-ejaw kard.

water-DEF invert-OBJPRO make.PST.3SG.

'[He] poured the water.'

The first example depicts a situation where the agent does the action intentionally. The second one can be used to describe either an intentional or unintentional action. The last one, quite the contrary, is solely used to depict a totally unintentional motion. 


\subsection{Experiment (2): Investigating the Goal-over-Source predominance hy- pothesis in Ilami placement and removal events}

As mentioned previously, Lakusta and Landau (2012) have investigated the the Goal-overSource predominance hypothesis in real-life events that can be described using manner of motion verbs. Replicating part of their methodology, we examine the goal-bias hypothesis in Ilami Kurdish placement and removal events at both descriptive and memory levels. We definitely aim to notice whether the goal-bias hypothesis is attested in either of the sub-experiments.

\subsubsection{Sub-experiment ( 2 a): A descriptive task}

The goal of this experiment is to measure how frequently llami Kurdish participants explicate goal and source expressions in placement and removal events, respectively.

\subsubsection{Stimuli and participants}

Respondents were requested to watch 37 researcher-made videos ( $M=3 \mathrm{sec}$ in length) portraying placement $(N=18)$ and removal events $(N=19)$ and then tell the researcher what they have seen. The events comprised of an actor putting a figure (e.g. book) on/in/at or taking it from some ground location with different manners of motion. Sources and goals were real objects such as wall, table, floor, etc. In addition to the 37 short videos, 2 warm-up clips, which were non-placement/-removal events, were also used. Ten naïve participants (30-60 years old), including five males and five females, were recruited for this task.

\subsubsection{Procedure}

The procedure was similar to that used in Experiment (1). Participants were instructed to watch the scenes depicting placement and removal events and tell the experimenter what they have observed. However, this experiment is definitely focused on the number of source and goal expressions explicated in the descriptions. Following Lakusta and Landau (2012), to avoid altering participants about the purpose of the experiment, we did not provide feedback during practice, and participants proceeded to test as soon as they watched the warm-up clips.

\subsubsection{Sub-experiment (2b): A non-linguistic memory task}

The purpose of this experiment is to show whether the Goal-over-Source predominance hypothesis is supported in a non-linguistic memory task. 


\subsubsection{Participants and stimuli}

The video set used in experiment (2a) was also used for this experiment. Additionally, for this experiment, matched clips were also used. Ten adults participated in this experiment, including five males and five females (25-60 years old). Following Lakusta and Landau (2012), none of these respondents participated in the previous experiments. As the video set are the same in sub-experiments (2a) and ( $2 b$ ), the recruitment of these naïve respondents assures us that participants will not supply goal and source expressions at ceiling levels. As already mentioned, there are also matched clips constructed for each of the placement or removal events. The matched events include events identical to the target event $(N=9)$, events with different goal paths $(N=9)$, events with different source paths $(N=9)$, events with different figures $(N=5)$ and events with different motions $(\mathrm{N}=5)$. The changes in the figures and motions were only used to complicate the task. It should be also pointed that four warm-up clips (e.g. sitting on a chair) were also used to acquaint the participants with the procedure.

\subsubsection{Procedure}

The participants were requested to watch the 37 video clips. The events comprised of an agent putting or taking a figure object to or from a physical ground. As stated earlier, the average length of the videos was 3 seconds and as soon as a video finished playing, the screen went black for $10 \mathrm{sec}-$ onds. Then the matched even started. Following Lakusta and Landau (2012), to interfere with the linguistic encoding, participants were requested to shadow a sequence of words or numbers being displayed from the computer. It was also considered that asking trivia questions can increase the complexity of the task. Then the participants were requested to judge whether the target and the matched events are the same or not. Their answers were recorded and they were scored accordingly.

\subsubsection{Results and discussion}

As far as experiment (2a) is taken into consideration, the linguistic goal-bias is observed in Ilami. According to our data in $94.97 \%$ of the placement events, goal is explicitly mentioned, whereas in only $40.8 \%$ of the removal events is the source explicated. As the Kurdish data show, it is common in Ilami Kurdish to imply the source of removal events. The following examples illustrate that regardless of the nature of the figure, agent, and manner of motion, the source path can be systematically implied:

(28) zan-ce kataw-ce [(dce nam-a kwamad-ce)]SOURCE dar-awardce doer. Woman-DEF book-DEF from into-EZ wardrobe-DEF out-take.PST.3SG out 'The woman took the book (out of the wardrobe).' 
(29) joeqap-a aks-ce $\quad[(d c e$ qej-e diwar-ce $)]$ SOURCE dor-award. this frame-EZ picture-DEF from on-EZ wall-DEF out-take.PST.3SG off. 'Here, [he] took the poster (off the wall).'

(30) dijoet-ce $\quad$ xwedkar-ce $\quad[($ dce ban-a mez-ce) $]$ SOURCE hezda.

girl-DEF pen-DEF from on-EZ table-DEF liftgive.PST.3SG.

'The girl took the pen (off the table).'

The omission of the source component in the examples illustrated above supports the fact that this component is a peripheral element, which only conveys old information. Conversely, the goal component in Ilami placement events often tends to be explicated, regardless of the nature of figure, ground, agent or manner of motion. The following examples are illustrative.

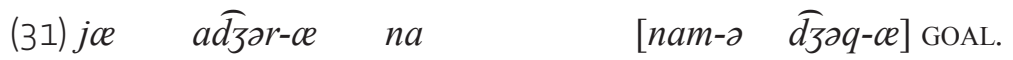

this brick-DEF put.PST.3SG in-EZ pot-DEF.

'[He] put the brick into the pot of water.'

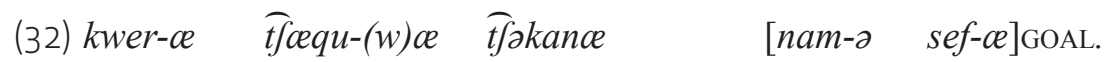

Boy-DEF knife-def insert.PST.3sg into-EZ apple-DEF.

'The boy inserted the knife into the apple.'

(33) dुam-ce na [mal-a mez- $\alpha]$ GOAL.

Bowl-DEF put.PST.3SG on-EZ table-DEF.

'[She] put the bowl on the table.'

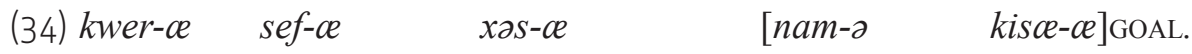

boy-DEF apple-DEF drop.PST.3sg-to inside-DEF bag-DEF.

'The boy dropped the apple into the bag.'

Ascan be observed, in all the examples presented above, the goal component is explicitly expressed. Cross-linguistically, llami Kurdish is similar to KuukThaayorre, Japanese, Swedish, Spanish, Basque, Moroccan Arabic, Tzeltal, Lowland Chontal and English language (see table 2 on the next page).

As can be seen in table 2, the aforementioned languages reveal evidence of attentional bias towards the endpoints of the events; however, some languages like Polish and Jahai do not reflect this dissymmetry. It is worth mentioning that the goal/source asymmetry can be observed in different domains, which do not necessarily overlap in different languages. For example, Kabata (2013) investigates the patterns of semantic extensions of goal- markers and source-markers in 24 languages, and concludes that Polish is amongst the languages which support the goal-over-source hypothesis. As for experiment (2b), it was found that in $90.57 \%$ of the placement events, goal is correctly matched, whereas in only $26.42 \%$ of the removal events is the source accurately matched. 


\section{TABLE 2}

Source vs. goal expression in different languages

\begin{tabular}{lll}
\multicolumn{1}{c|}{ LANGUAGE } & GOAL IN PLACEMENT & SOURCE IN REMOVAL \\
\hline Japanese (Ishibashi, 2012) & $95.2 \%$ & $51.5 \%$ \\
\hline Ilami Kurdish & $94.97 \%$ & $40.8 \%$ \\
\hline Swedish (Gullberg \& Burenhult, 2012) & $91 \%$ & $75 \%$ \\
\hline Kuuk Thaayorre (Gaby, 2012) & $85 \%$ & $31 \%$ \\
\hline Basque (Ibarretxe-AntuÑano, 2012) & More & Less \\
\hline Spanish (Ibarretxe-AntuÑano, 2012) & More & Less \\
\hline Moroccan Arabic (Nouaouri, 2012) & More & Less \\
\hline Tzeltal (Brown, 2012) & More & Less \\
\hline Lowland Chontal (O’Connor, 2012) & More & Less \\
\hline English (Stefanowitsch \& Rohde, 2004) & More & 97.2\% \\
\hline Kalasha (Petersen, 2012) & $96.6 \%$ & \\
\hline Polish (Kopecka, 2012) & & No difference \\
\hline Jahai (Burenhult, 2012) & No difference & \\
\hline
\end{tabular}

As can be seen above, in sub-experiments (2a) and (2b), the goal component obtained a higher score compared to the source path. This supports the fact that attentional bias towards the goalpaths is observed at both levels, i.e. language and cognition. The above findings also support the previous research on the non-linguistic basis of the Goal-over-Source principle (see, for example, Ikegami, 1982, 1987; Ungerer \& Schmid, 1996; Verspoor et al., 1998; Lakusta \& Landau, 2005; Lakusta et al., 2006; Regier \& Zheng, 2007). For example, Regier and Zheng (2007) argue that adults discriminate the endpoints of spatial motion events more readily than they do event beginningssuggesting a non-linguistic attentional bias toward endpoints. Lakusta et al. (2007) also report that 12-month-old infants privilege goals over sources. Lakusta and Landau (2005) argued that this source vs. goal asymmetry is driven by cognitive factors, namely a cognitive bias in favor of goals. Hence, the endpoint of events appears to be of more importance in comparison with the starting point. In other words, it is already known by the speaker and addressee, where the figure object (e.g. a tea cup) is located, permitting them to omit the source (e.g. the table) in the removal event systematically. However, the endpoint of a placement event is less predictable and presupposed, encouraging the speaker to explicate this component. Therefore, clarity as a key factor of a successful conversation necessitates the explicit expression of the goal of motion. This might be the major reason behind the low tolerance of goal omission in Ilami Kurdish.

Another characteristic worth mentioning is that, the order of source and goal is not arbitrary but rather an iconic one. In removal events, the source is always expressed at a pre-ver- 
bal position, whereas in placement events, which are goal-oriented, the goal component is encoded after the verb. These iconic orderings are represented in the following figures.

\section{FIGURE 3}

Iconicity of source-verb in removal events of Ilami Kurdish

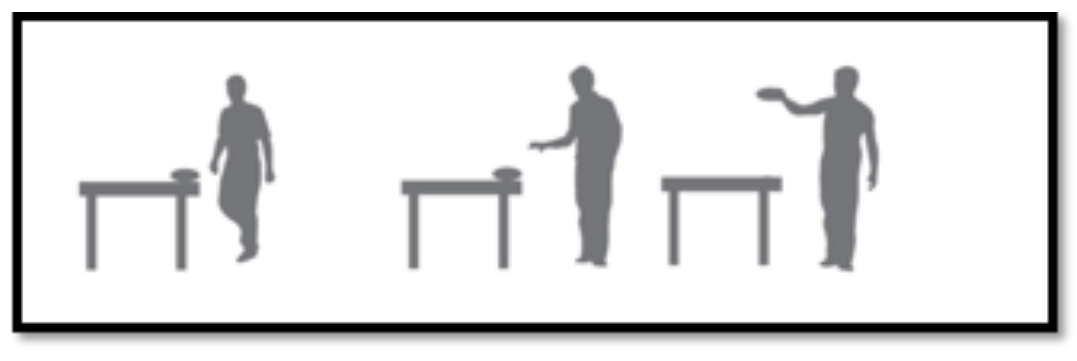

\section{FIGURE 4}

Iconicity of verb-goal in placement events of Ilami Kurdish

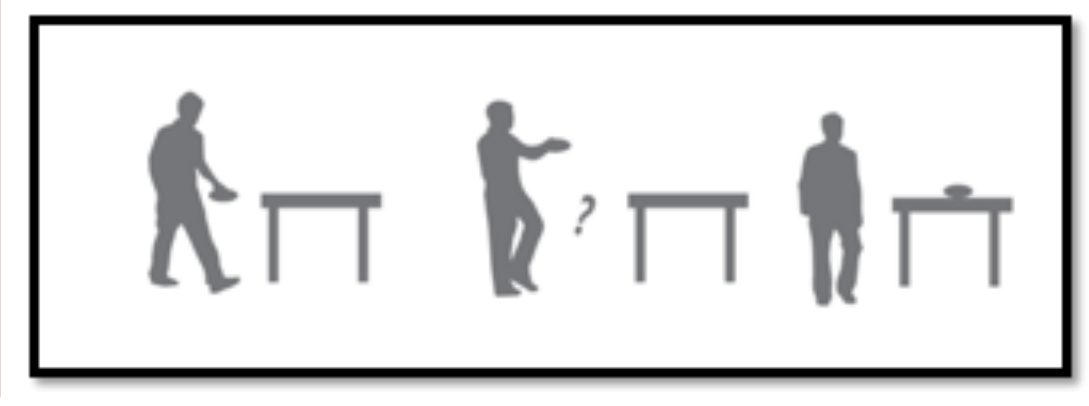

It can be concluded that speakers cognitively link their experiences concerning placement and removal events with syntactic structures and exhibit this connection through the iconic ordering of the source or goal components with respect to the verb. This iconic representation of source and goal components is not confined to llami Kurdish. For example, there is a similar temporal iconicity observed in Mandarin Chinese (Haiman, 1985; Tai, 1985), based on which the surface order of the syntactic units matches the temporal order of the placement events - holding or handling the object and then placing it at or removing it from a location (Chen, 2012). The following examples from Mandarin Chinese illustrate this iconicity:

(35) ta1 ba3 zhuan1tou [cong2 shui3 li3] SOURCE na2-chu1-lai2.

she ba brickfrom waterinside take-exit-come.

'She took the brick from the water.'

In this example, congz shuiz liz "from water" is considered the source of motion, which is encoded at the pre-verbal position. The information concerning the goal of motion is always encoded at a post-verbal position, which can be seen below: 
(36) tal ba3 mu4kuai4 dao4 [zai4 di4 shang4]GOAL.

he bawood.block pour at ground on.

'He poured the wooden blocks on the ground.'

In example (36), the goal component is expressed through the adjunct coverb phrase zai4 di4 shang 4 "at ground on", which is encoded after the verb. The iconic representation of source and goal in Ilami Kurdish and Mandarin Chinese shows that, since goal component is taken for granted by the interlocutor(s), it comes first. In contrast, the goal path, which is assumed to be non-presupposed, is lexicalized at a post-verbal position, giving more time to be successfully processed by the interlocutor(s). Consequently, the temporal iconicity observed in Ilami Kurdish and Mandarin Chinese facilitates mental processes concerning placement and removal events and guarantees a more successful interaction.

\subsection{Further evidence from argument structure}

As stated earlier, goal information, which is syntactically a prepositional phrase, is an obligatory constituent in Ilami placement events. Should we omit this part of a placement event, the sentence would be ill-formed. Consider the following examples:

(37) $s e \bar{e}-\propto \quad$ na $\quad[$ nam-ə $\quad$ kisce $-\propto]$ GOAL.

apple-def put.PST.3sg in-EZ bag-DEF.

'[The man] put the apple into the bag.'

(38) ?sēf-ce na.

apple-dEF put.PST.3SG.

'[The man] put.'

In (37), the goal of the motion, which is syntactically the PP of the sentence, is explicated, and this leads to the construction of a well-formed sentence. However, when the goal phrase is omitted, the outcome would be a marked sentence with an incomplete meaning (example 38). On the contrary, analyzing the removal events, we figured out that explicating the source information is not obligatory in such constructions. So, we may consider the source phrase as an adjunct. The following removal events are grammatical with and without the source component:

(39) sēf-ce [(dce nam-a kisce-c) $]$ SOURCE dar-award. apple-def from in-EZ bag-DEFout-bring.PST.3sG.

'[The man] took the apple out of the bag.' 
(40) sēf-ce dar-award.

apple-dEF out-bring.PST.3SG.

'[The man] took the apple out.'

It can be said that goal and source components are the obligatory semantic arguments of placement and removal verbs, respectively. So, placement and removal verbs are different from those verb classes (e.g. manner verbs), which lack these arguments in their semantic or logical structure. Nonetheless, only the goal phrase can be considered the syntactic argument of the verb, since the prepositional phrase encoding the source path is always implied by Ilami speakers. These patterns of use can be explained through two competing motivations in language, i.e. iconicity and economy. Based on the economy principle, what is known or conveys redundant information does not need to be encoded. As mentioned before, the source component conveys old information, and this causes speakers to imply this element regularly, which is economically motivated (even though, this component is an obligatory semantic argument of the removal verbs). On the other hand, the goal component is an obligatory semantic and syntactic argument at the same time, as the speakers frequently tend to explicate it in placement events. It seems that being a semantic and syntactic argument at the same time has an iconic motivation. In other words, what is obligatory (and more salient) in the semantic structure is also obligatory in the syntactic structure of the verb. Cross-linguistically, this pattern of use is attested in such languages as Japanese, Swedish, Basque, Spanish and Moroccan Arabic, all of which support the Goal-over-Source predominance hypothesis (Narasimhan et al., 2012). At least as a universal tendency (if not in its strict sense), it can be said that in those languages in which the goal-bias is observed, the goal component is an obligatory argument, while the source phrase is an adjunct.

\section{Conclusion}

The present study set out to explore the linguistic features of placement and removal events in Ilami Kurdish. The results revealed that, like many other languages, there is an asymmetric relationship in favour of placement predicates in Ilami Kurdish. There are more finegrained placement verbs in Ilami Kurdish, suggesting that placement is more salient than removal events. When reviewing the data, we found that many factors such as the shape and size of the figure object, direction and manner of motion, and (un)intentionality of the agent, are determinant in choosing one type of verb. Regarding the Goal-over-Source predominance hypothesis, we conducted descriptive and memory tasks to determine whether this hypothesis is supported in linguistic and non-linguistic levels. It was shown that there is a preferential bias towards the goal at the linguistic as well as non-linguistic levels. In the mentioned experiments, the goal component was more frequently mentioned and more accurately matched, respectively. This supports the hypothesis that the goal-bias in language 
has roots in human cognition. Furthermore, the linguistic encoding of Ilami Kurdish source and goal phrases represents an iconic ordering, since these components are always encoded pre- and post-verbally, respectively. This highlights the trivial (i.e. redundant) nature of source, which comes first, and emphasises the pivotal role of goal information in the conversation flow, which in this way is more successfully perceived. It was also discussed that although in the languages which support the Goal-over-Source predominance hypothesis the goal and source components are semantically required for the perception of placement and removal events, they may be syntactically considered as obligatory argument and adjunct, respectively. Finally, these patterns of use were explained through the economy and iconicity principles, which again highlight the cognitive salience of the goal component in comparison with the source expression.

\section{List of Abbreviations}

$\begin{array}{ll}3 & \text { 3rd PERSON } \\ \text { AGR } & \text { AGREEMENT } \\ \text { DEF } & \text { DEFINITE } \\ \text { EZ } & \text { EZAFE } \\ \text { NP } & \text { NOUN PHRASE } \\ \text { OBL } & \text { OBLIQUE } \\ \text { OBJ } & \text { OBJECT(IVE) } \\ \text { PST } & \text { PAST TENSE } \\ \text { POSS } & \text { POSSESSIVE } \\ \text { PP } & \text { PREPOSITIONAL PHRASE } \\ \text { PRO } & \text { PRONOUN } \\ \text { SG } & \text { SINGULAR } \\ \text { SEM } & \text { SEMANTIC } \\ \text { SUBJ } & \text { SUBJECT } \\ \text { SYN } & \text { SYNTACTIC } \\ V & \text { VERB } \\ \text { VP } & \text { VERB PHRASE }\end{array}$

\section{References}

Asatrian, G., 2009: "Prolegomena to the study of the Kurds", Iran and the Caucasus 13, 1- 58.

Bynon, Th., 1979: "The ergative construction in Kurdish", Bulletin of the School of Oriental and African Studies 42 (2), 211-224. 
Brown, P., 2012: "To 'put' or to 'take'? Verb semantics in Tzeltal placement and removal expressions" in A. Kopecka \& B. NARASIMHAN (eds.): Events of putting and taking: A crosslinguistic perspective, Amsterdam: Benjamins, 55-78.

Bowerman, M. M. Gullberg, A. Majid, \& B. Narasimhan, 2004: "Put project: The crosslinguistic encoding of placement events" in A. MajID (ed.): Field Manual, vol. 9, Nijmegen: Max Planck Institute for Psycholinguistics, 10-24.

Burenhult, N., 2012: "The linguistic encoding of placement and removal events in Jahai" in A. Kopecka \& B. Narasimhan (eds.): Events of putting and taking: A crosslinguistic perspective, Amsterdam: Benjamins, 21-36.

BybeE, J., 2001: Phonology and language use, Cambridge: Cambridge University Press.

CHEN, J., 2012: "She from bookshelf take-descend-come the box': Encoding and categorizing placement events in Mandarin" in A. KoPECKA \& B. NARASIMHAN (eds.): Events of putting and taking: A crosslinguistic perspective, Amsterdam: Benjamins, 37-54.

Cifuentes Férez, P., 2008: Motion in English and Spanish: A perspective from cognitive linguistics, typology and psycholinguistics. PhD thesis, Universidad de Murcia.

GaBY, A., 2012: "The Thaayorre lexicon of putting and taking" in A. Kopecka \& B. Narasimhan (eds.): Events of Putting and Taking: A crosslinguistic perspective, Amsterdam: Benjamins, 233-252.

GunteR, M., 2004: Historical Dictionary of the Kurds, Maryland: Scarecrow Press Inc.

Goldberg, A., D. Casenhiser, \& N. Sethuraman, 2004: "Learning argument structure generalizations", Cognitive Linguistics 15 (3), 289-316.

GoldberG, A. E., 1995: Constructions: A construction grammar approach to argument structure, Chicago: University of Chicago Press.

Gleitman, L., 1990: “The structural sources of verb meanings”, Language Acquisition 1, 3-55.

Gullberg, M., \& N. Burenhult, 2012: "Probing the linguistic encoding of placement and removal events in Swedish" in A. Kopecka \& B. Narasimhan (eds.): Events of putting and taking: A crosslinguistic perspective, Amsterdam: Benjamins, 167-182.

Halman, J., 1985: Iconicity in Syntax, Typological Studies in Language 6, Amsterdam: John Benjamins.

Hickmann, M., H. Henriëtte, S. Efstathia, I. Tatiana, \& L. Yinglin, 2012: "Space and language typology: Encoding motion across languages".

Ikegamı, Y., 1987: "Source’ vs. 'Goal': A case of linguistic dissymmetry” in R. DiRven \& G. Radden (eds.): Concepts of Case, Tübingen: Gunter Narr, 122-146. 
IkEgami, Y., 1982: "Source vs. Goal: A case of linguistic dissymmetry" in R. N. St. ClalR \& W. von Raffler-Engel (eds.): Language and Cognitive Styles: Patterns of Neurolinguistic and Psycholinguistic Development, Lisse: Swets \& Zeitlinger, 292-308.

Ibarketxe-Antuñano, I., 2012: "Placement and removal events in Basque and Spanish" in A. Kopecka \& B. NarasimHAN (eds.): Events of putting and taking: A crosslinguistic perspective, Amsterdam: Benjamins, 123-144.

ISHIBASHI, M., 2012: "Expression of 'putting' and 'taking' events in Japanese: 'Asymmetry of Source and Goal' revisited” in A. KopeCKA \& B. NARASIMHAN (eds.): Events of putting and taking: A crosslinguistic perspective, Amsterdam: Benjamins, 253-272.

IWATA, S., 2008: Locative Alternation: A Lexical-Constructional Approach, Constructional Approaches to Language 6, Amsterdam and Philadelphia: John Benjamins.

KopeCKA, A., 2012: "Semantic granularity of placement and removal expressions in Polish" in A. Kopecka \& B. Narasimhan (eds.): Events of putting and taking: A crosslinguistic perspective, Amsterdam: Benjamins, 327-348.

LAKUSTA, L., \& B. LANDAU, 2005: "Starting at the end: The importance of goals in spatial language", Cognition 96, 1-33.

Lakusta, L., \& B. LANDAU, 2012: "Language and Memory for Motion Events: Origins of the Asymmetry between Source and Goal Paths”, Cognitive Science 36 (3), 517-544.

Lakusta, L., L. Wagner, K. O’Hearn, \& B. Landau, 2007: “Conceptual foundations of spatial language: Evidence for a goal bias in infants", Language Learning and Development 3, 179-197.

Lakusta, L., H. Yamada, L. Smith, \& B. Landau, 2006: “Cross-linguistic evidence for a goal/source asymmetry: The case of Japanese", poster presented at the Annual Meeting of the XVth Biennial International Conference on Infant Studies, Westin Miyako, Kyoto, Japan.

MaIID, A., \& M. Bowerman, 2007: "Cutting and breaking events: A cross-linguistic perspective", special issue of Cognitive Linguistics 18 (2).

MackCenzie, D. N., 1963: “Kurmandzi, Kurdi, Gurani”, Narody Azii I Afriki 1, 162- 170.

Narasimhan, B., A. Kopecka, M. Bowerman, M. Gullberg, \& A. Majid, 2012: "Putting and taking events: A crosslinguistic perspective" in A. KopeCKA \& B. NARASIMHAN (eds.): Events of putting and taking: A crosslinguistic perspective, Amsterdam: Benjamins, 1-18.

NouaourI, N., 2012: "The semantics of placement and removal predicates in Moroccan Arabic" in A. Kopecka \& B. Narasimhan (eds.): Events of putting and taking: A crosslinguistic perspective, Amsterdam: Benjamins, 99-122. 
O'Connor, L., 2012: "Take it up, down, and away: Encoding placement and removal in Lowland Chontal" in A. KopeckA \& B. NARAsImHAN (eds.): Events of putting and taking: A crosslinguistic perspective, Amsterdam: Benjamins, 297-326.

OranskIJ, I., 1979: Iranskieyazyki v istorčeskomosveščenii, Moskva: Nauka.

Petersen, J. H., 2012: "How to put and take in Kalasha" in A. Kopecka \& B. Narasimhan (eds.): Events of putting and taking: A crosslinguistic perspective, Amsterdam: Benjamins, 349-366.

RegieR, T., \& Zheng, M., 2007: "Attentions to endpoints: A cross-linguistic constraint on spatialmeaning", Cognitive Science 31, 705-719.

SLoBIN, D. I., 2004: "The many ways to search for a frog: Linguistic typology and the expression of motion events" in S. StrömQvist \& L. Verhoeven (eds.): Relating events in narrative: Typological and contextual perspectives in translation, Mahwah, NJ: Lawrence Erlbaum, 219-257.

Stefanowitsch, A., \& A. Rohlde, 2004: "The goal bias in the encoding of motion events" in G. Radden \& K.-U. Panther (eds.): Studies in linguistic motivation, Berlin: Mouton de Gruyter, 249-267.

TAl, J., 1985: "Temporal sequence and Chinese word order" in J. HAImAN (ed.): Iconicity in Syntax, Typological Studies in Language 6, Amsterdam: John Benjamins, 49-72.

TALMY, L., 2000: Toward a Cognitive Semantics I, II, Cambridge MA: The MIT Press.

TALmy, L., 1985: "Lexicalization patterns: Semantic structure in lexical forms” in T. Shopen (ed.): Language Typology and Syntactic Description, vol. 3: Grammatical Categories and the Lexicon, Cambridge: Cambridge University Press, 57-146.

Ungerer, F., \& H. J. Schmid, 1996: An Introduction to Cognitive Linguistics, London: Longman.

Verspoor, M., R. Dirven, \& G. Radden, 1998: "Putting concepts together: Syntax" in R. DiRven \& M. Verspoor (eds.): Cognitive Exploration of Language and Linguistics, Cognitive Linguistics in Practice 1, Amsterdam: John Benjamins, 79-105. 